Article

\title{
A Study of the Interactions of Activated Carbon-Phenol in Aqueous Solution Using the Determination of Immersion Enthalpy
}

\author{
Ana María Carvajal-Bernal ${ }^{1}$, Fernando Gómez-Granados ${ }^{1}$, Liliana Giraldo ${ }^{1}$ and \\ Juan Carlos Moreno-Piraján 2,* (i) \\ 1 Departamento de Química, Facultad de Ciencias, Universidad Nacional de Colombia, Sede Bogotá, \\ Carrera 45 No 45-03, CP 11321142 Bogotá, Colombia; amcarvajalb@unal.edu.co (A.M.C.-B.); \\ fagomez@unal.edu.co (F.G.-G.); lgiraldogu@unal.edu.co (L.G.) \\ 2 Laboratorio de Sólidos Porosos y Calorimetría, Departamento de Química, Facultad de Ciencias, \\ Universidad de los Andes Carrera 1 No 18 A-10, CP 110311484 Bogotá, Colombia \\ * Correspondence: jumoreno@uniandes.edu.co; Tel.: +57-13394949 (ext. 3465)
}

Received: 23 March 2018; Accepted: 7 May 2018; Published: 23 May 2018

\begin{abstract}
In this study, the amount of phenol adsorbed between 0 and $10 \mathrm{mmol} \cdot \mathrm{L}^{-1}$ during an immersion calorimetric experiment is compared with the adsorption that takes place once phenol adsorption reaches the solid-solution equilibrium. The activated carbons used were prepared by impregnation of one obtained from coconut shell with solutions of nitric and phosphoric acid, nitric acid with subsequent reflux in ammonium hydroxide solution, and carbonisation in a nitrogen atmosphere at 1073, 1173, and $1273 \mathrm{~K}$. The phenol/activated carbon interactions during the calorimetric experiment and in equilibrium were studied using a modified Langmuir model. The values of the BET surface area for the samples were between 469 and $1113 \mathrm{~m}^{2} \cdot \mathrm{g}^{-1}$, micropore volumes were between 0.18 and $0.43 \mathrm{~cm}^{3} \cdot \mathrm{g}^{-1}$, and the distribution of pore size was between 0.3 and $1.4 \mathrm{~nm}$. The interactions between water and activated carbons determined by immersion enthalpies were between -11.0 and $-24.8 \mathrm{~J} \cdot \mathrm{g}^{-1}$, which showed that the treatments modified the surface chemistry of activated carbon. The results show that the presence of nitrogen as a different heteroatom to oxygen on the activated carbon surface favors the phenol adsorption rate, and this process is $97 \%$ complete during the calorimetric experiment, indicating that it is an enthalphy-driven processes.
\end{abstract}

Keywords: immersion calorimetry; adsorption; activated carbon; phenol; entalphy

\section{Introduction}

Activated carbons are materials characterised by a porous internal structure that gives them great surface area, volume, and distribution of pore size; additionally, they have functional groups that are prepared at the edges of grapheme layers and have been used in industrial processes that involve the adsorption of contaminants at the liquid-solid interface [1]. One of the most studied pollutants in adsorption from solution is phenol, because it is normally present as a residue in water sources, since it is part of the effluent from chemical plants, oil refineries, the processing of paper pulp, gasification, the production of phenolic resins, and paintings, among others [2].

The surface of activated carbon is heterogeneous, composed of both hydrophobic and hydrophilic regions, with a variety of functional groups that are mainly oxygenated. The process of adsorption has been described using different mechanisms, such as van der Waals interactions, hydrogen bonds, electrostatic interactions, ion exchange, and hydrophobic links. Many organic molecules like phenol possess hydrophilic and hydrophobic regions. The polar groups in molecules tend to interact with polar groups on the activated carbon surface using hydrogen bonds, permanent dipoles, and permanent 
dipole-induced dipole or ion-ion interactions, which are enthalpy-driven processes, while the non-polar portions of the molecule are adsorbed onto the basal surface of activated carbon through entropy-driven hydrophobic links [3].

When activated carbon is placed in contact with a liquid there are different phenomena such as wetting, penetration of the molecules into the pores, and the formation of a layer that involves specific interactions; these can be studied by immersion calorimetry, because the heat exchanged during this processes provides important information about adsorbent-adsorbate interactions [4-8].

This study seeks to compare specific and non-specific interactions between superficially modified activated carbons and phenol in adsorption during immersion calorimetry at equilibrium. An activated carbon was modified by impregnation with solutions of nitric acid, phosphoric acid, nitric acid with subsequent reflux in solution of ammonium hydroxide, and carbonisation in a nitrogen atmosphere to 1073,1173 , and $1273 \mathrm{~K}$. The immersion enthalpy was determined in aqueous solutions of phenol in a range from 0.1 to $10 \mathrm{mmol} \mathrm{L}^{-1}$. The phenol adsorption during the calorimetric process of immersion was compared with the adsorption obtained when it reached equilibrium, taking into account that there is an effect on the interaction due to contact time; in addition, it verifies the validity of the energy interaction, which is determined by calorimetry with the adsorption that is measured at equilibrium.

\section{Materials and Methods}

\subsection{Preparation of the Activated Carbons}

The study began with an activated carbon, prepared from coconut shell, and subjected to the following different treatments: (1) impregnated with a solution of $60 \%$ nitric acid (nitric acid p.a. $65 \%$ Merck) at $291 \mathrm{~K}$; (2) impregnated with a solution of $60 \%$ phosphoric acid (ortho-phosphoric acid p.a. $85 \%$ ) at $291 \mathrm{~K}$, in a method described in other works [9]; (3) impregnated with nitric acid and treated by reflux, in ammonium hydroxide concentrated solution to $373 \mathrm{~K}$ for $24 \mathrm{~h}$ (previous samples were washed with deionised water until $\mathrm{pH}$ constant, and then dried to a constant weight); and (4) the original activated carbon was heated in a horizontal oven at a heating rate of $5{ }^{\circ} \mathrm{C} \mathrm{min}^{-1}$ up to temperatures of 1073,1173 , and $1273 \mathrm{~K}$, respectively. Once the oven reached the relevant temperature, the samples were maintained for two hours in a nitrogen atmosphere. In total, seven samples were obtained, including the original activated carbon.

\subsection{Identification of Samples}

The following activated carbons were identified: activated carbon produced from coconut shell, used as a starting material $(\mathrm{G})$; granular activated carbon impregnated with nitric acid solution (GN); granular activated carbon impregnated with nitric acid solution and subsequent reflux in ammonium hydroxide solution (GNA); granular activated carbon impregnated with phosphoric acid solution (GP); and granular activated carbons treated thermally in a nitrogen atmosphere to $1073,11731273 \mathrm{~K}$, as $\mathrm{GC}_{1073}, \mathrm{GC}_{1173}$, and $\mathrm{GC}_{1273}$, respectively.

\subsection{Characterisation of Activated Carbon Samples}

The textural properties of activated carbons were calculated from the isotherms of nitrogen adsorption, $\mathrm{N}_{2}$, at $77 \mathrm{~K}$ obtained on a Quantachrome IQ equipment. The surface area (S) was assessed using the Modified Brunauer, Emmet, and Teller (M.B.E.T.) model. The micropore volume, Vo, was obtained using Dubinin-Astakhov (DA) and Dubinin-Radushkevich (DR) models in order to compare values obtained with these models. The total volume of pores, $\mathrm{V}_{\mathrm{T}}$, was determined using the Quenched Solid Density Functional Theory (QSDFT) and the volume of mesopore, $\mathrm{V}_{\mathrm{m}}$, by the difference between the total volume and the micropore volume [10]. 


\subsection{Determination of Phenol Adsorption in the Immersion Solutions}

As mentioned previously, the objective of this work was to compare the amount of phenol adsorbed during the calorimetric experience of immersion and adsorption that takes place once phenol adsorption reaches the solid-solution equilibrium.

The adsorption isotherm was prepared using different solutions in the range of 1 to $10 \mathrm{mmol} \cdot \mathrm{L}^{-1}$ prepared from phenol GR for the ACS analysis. European Pharmacopoeia Reagent. $10 \mathrm{~mL}$ of phenol solution was placed in the calorimetric cell, and, when the system reached thermal equilibrium, $0.1 \mathrm{~g}$ of previously degassed activated carbon was placed in the cell containing the phenol solution; the adsorption experiment was continued until the system reached equilibrium.

The phenol concentration in the solution was determined by UV Spectroscopy using Thermo Spectronic Genesys 5 equipment to a $\lambda_{\max }$ of $268 \mathrm{~nm}$ once the calorimetric experiment was finished. The quantity of phenol adsorbed at the end of the calorimetric experiment $q_{e}\left(\mathrm{mmol} \cdot \mathrm{g}^{-1}\right)$ was calculated using the following Equation:

$$
q_{e}=V \frac{C_{e}-C_{0}}{m}
$$

in which $C_{0}$ and $C_{e}\left(\mathrm{mmol} \cdot \mathrm{L}^{-1}\right)$ are the initial and final phenol concentrations, respectively, $V(\mathrm{~L})$ is the solution volume in the immersion cell $(10 \mathrm{~mL})$, and $m(\mathrm{~g})$ is the activated carbon weight.

The adsorption obtained during the calorimetric experiment was compared with the results of phenol adsorption until equilibrium.

\subsection{Immersion Enthalpy Determination of Activated Carbons in Phenol Aqueous Solutions}

The immersion enthalpy of the activated carbon-phenol solution system was determined to $291 \mathrm{~K}$ in a Tian type heat conduction calorimeter built in the laboratory; this isothermal calorimeter uses thermopiles of semiconductor materials as thermal sensors, with a stainless steel cell with a capacity of $10 \mathrm{~mL}$, in which the immersion fluid is placed (phenol solution). Energy transferred as heat by the solid-liquid contact was determined by the measurement of electric potential. Thermal balance was realised when the variation of potential reached around $\pm 3 \mu \mathrm{V}$. Here, $0.1 \mathrm{~g}$ of activated carbon was previously degassed and isolated in a vacuum glass ampoule, and then plunged into the immersion fluid; the electric potential was recorded until a baseline was obtained. This indicates that the thermal equilibrium between the system and the surrounding area has been obtained. Finally, an electrical work was dissipated through a heating resistor contained within the immersion cell with which the electrical calibration was performed. The immersion enthalpy was obtained from the integration of the electric potential curve as a function of time for the process of immersion and its comparison with the calibration curve [11]. The equation for determining the immersion enthalpy, $\Delta H_{i m}\left(\mathrm{~J} \cdot \mathrm{g}^{-1}\right)$, from the data obtained is

$$
\Delta H_{i m}=\frac{V * I * t * A_{i m}}{m * A_{c a l}}
$$

in which $V(\mathrm{~V})$ is the heating potential, and $(A)$ is the current intensity applied on the heating resistor in a time $t$ (s) during the electrical calibration. $A_{i n m}$ is the area under the curve that corresponds to the energy transferred as heat during the immersion process, and $A_{c a l}$ is the area under the curve produced during the electrical calibration.

\subsection{Phenol Adsorption until Equilibrium}

The phenol isotherms were prepared using the same phenol concentration as the calorimetric experiment. Here, $50 \mathrm{~mL}$ of each solution was placed in a series of flasks containing $0.1 \mathrm{~g}$ of activated carbon; the samples included a blank of activated carbon. The flasks were stored at $291 \mathrm{~K}$ for 15 days, since that period had been previously determined to be necessary to reach equilibrium. The phenol concentration in the solution was determined by UV Spectroscopy on Thermo Spectronic Genesys 5 equipment to $\lambda_{\max }$ of $268 \mathrm{~nm}$; the quantity of phenol adsorbed was calculated using Equation (1). 


\section{Results and Discussion}

\subsection{Sample Characterisation}

Table 1 presents the results obtained from adsorption isotherms of nitrogen to $77 \mathrm{~K}$. Surface area was calculated using the M.B.E.T. model; Figure 1 shows the optimization of the fit of the adsorption data to the BET model; here, it is possible to see that the optimal range is between $3.08 \times 10^{-3}$ and $4.8 \times 10^{-2}$ of $\mathrm{P} / \mathrm{P}^{0}$; this range is different to the typical range between 0.05 and 0.35 used for calculate the BET area, and the adjustment permit to obtain positive values for the $C$ parameter related to adsorption energy [12]. The micropore volume was obtained with (DR) and (DA) models [13]; the mesopore volume was obtained by applying the BJH model; the pore radius and the total volume of pore $\mathrm{V}_{\mathrm{T}}$ were calculated by applying Density Functional Theory (DFT).

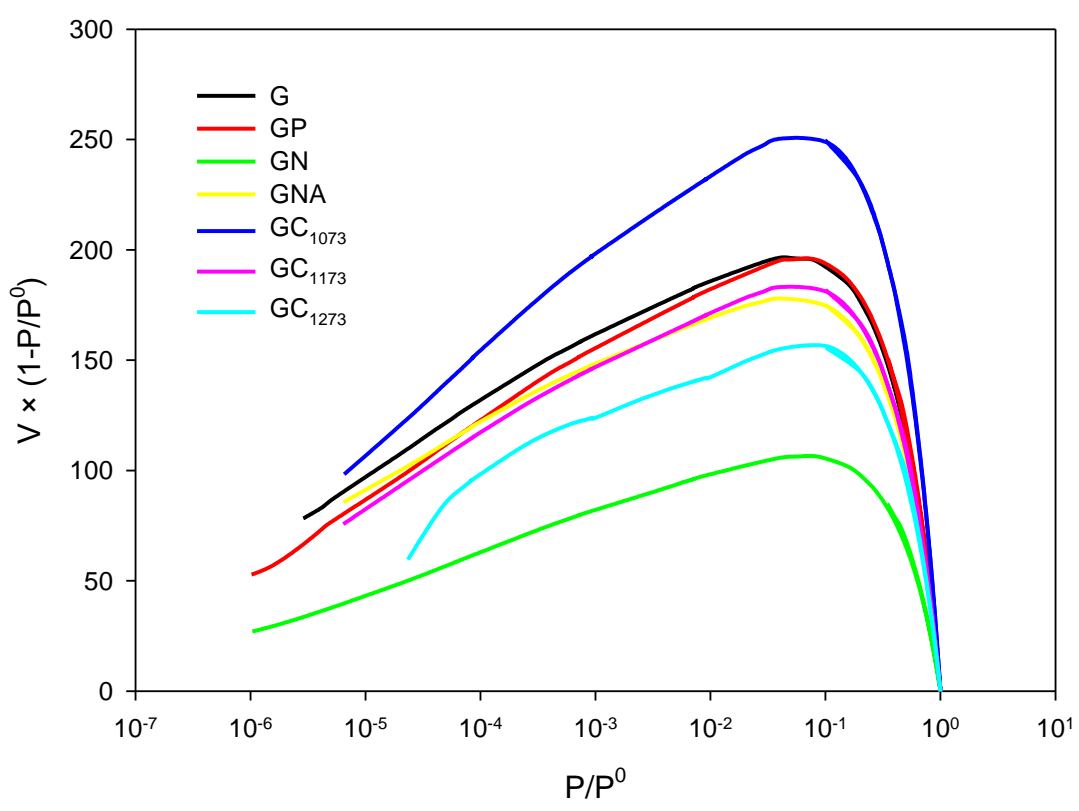

Figure 1. Optimization of the BET range.

Table 1. Textural Characterisation of activated carbons obtained from the N2 adsorption isotherm at $77 \mathrm{~K}$.

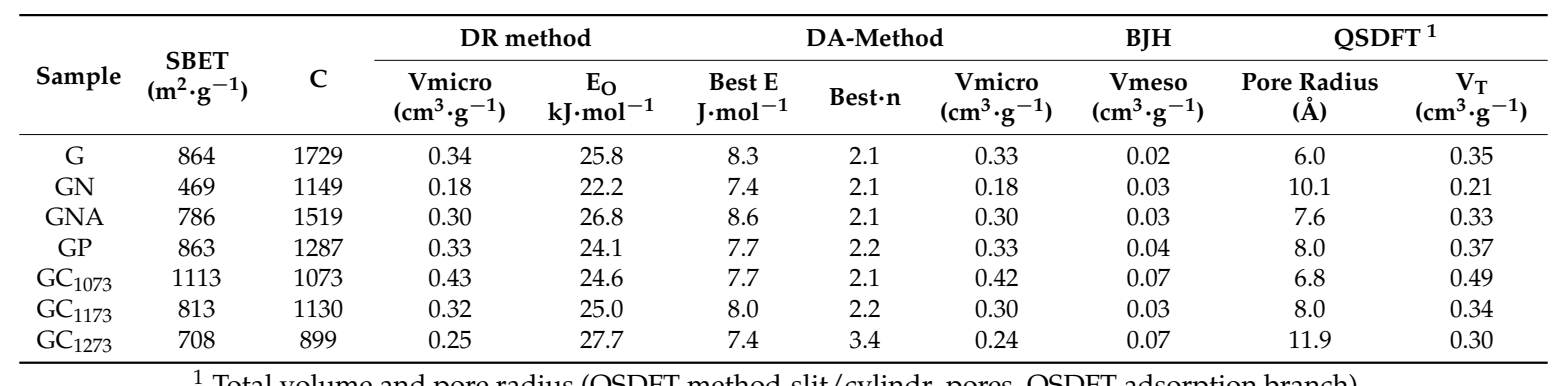

${ }^{1}$ Total volume and pore radius (QSDFT method-slit/cylindr. pores, QSDFT adsorption branch).

Table 1 shows that the activated carbons presented pore radius lower than $0.20 \mathrm{~nm}$, which indicates that these materials are microporous according to the classification of IUPAC [14]. It is also noted that the different impregnations modified the surface area of the original activated carbon G. The most significant changes were seen when the activated carbon was impregnated with nitric acid (sample GN) and when it was carbonised at $1073 \mathrm{~K}$ (sample $\mathrm{GC}_{1073}$ ). The treatment with nitric acid at $291 \mathrm{~K}$ generated a decrease in the surface area of around 54\%; different studies show that the impregnation with this agent produces oxidation on the surface of the activated carbon accompanied by 
a decrease of surface area and microporosity, and an increase of oxygen containing functional groups, particularly carboxylic groups [15]. When the pre-oxidised activated carbon GN is modified by reflux with ammonium hydroxide solution (sample GNA), it is observed that the area and the microporosity increase again, which suggests that there is an accumulation of nitric acid trapped in the micropores in the GN sample, which might mean that during the nitrogen adsorption, this cannot access all surfaces and would interfere with nitrogen molecules' homogeneous coverage, and consequently with area and micropore volume calculations. When acid groups are modified through the formation of amides, amines, imides, and pyrrolic and quaternary nitrogen groups $[16,17]$, by reflux with ammonia solution (sample GNA), this favours the adsorption of nitrogen more evenly over the surface.

Regarding activated carbon heat treatment to $1073 \mathrm{~K}$, the surface area increases to $28 \%$; this indicates that the carbonisation process at this temperature allows access to new microporosity. This can be seen in Table 1 by the values obtained for this parameter. It is important to emphasise that heat treatments at higher temperatures of 1173 and $1273 \mathrm{~K}$ generate a decrease in the surface area accompanied by the respective loss of microporosity that can be associated with the loss of oxygenated groups on the surface.

In the textural parameter determination from (DR) and (DA), models were evidenced that when the energetic heterogeneity described by the $n$ factor of the (DA) equation approached 2 , as in the DA model; the pore volumes calculated from both models coincide. With regard to the micropores' energy given by the E parameter of the (DA) equation compared with the adsorption energy Eo of the (DR) equation, it is noted that the values of Eo from the DR model are approximately three times greater than those calculated by the DA model. This comportment is indicative of the increase in the energy of the micropores when chemistry and geometric heterogeneity increase; it was generated by the impregnation process. Figure 2 shows the relationship between these two parameters.

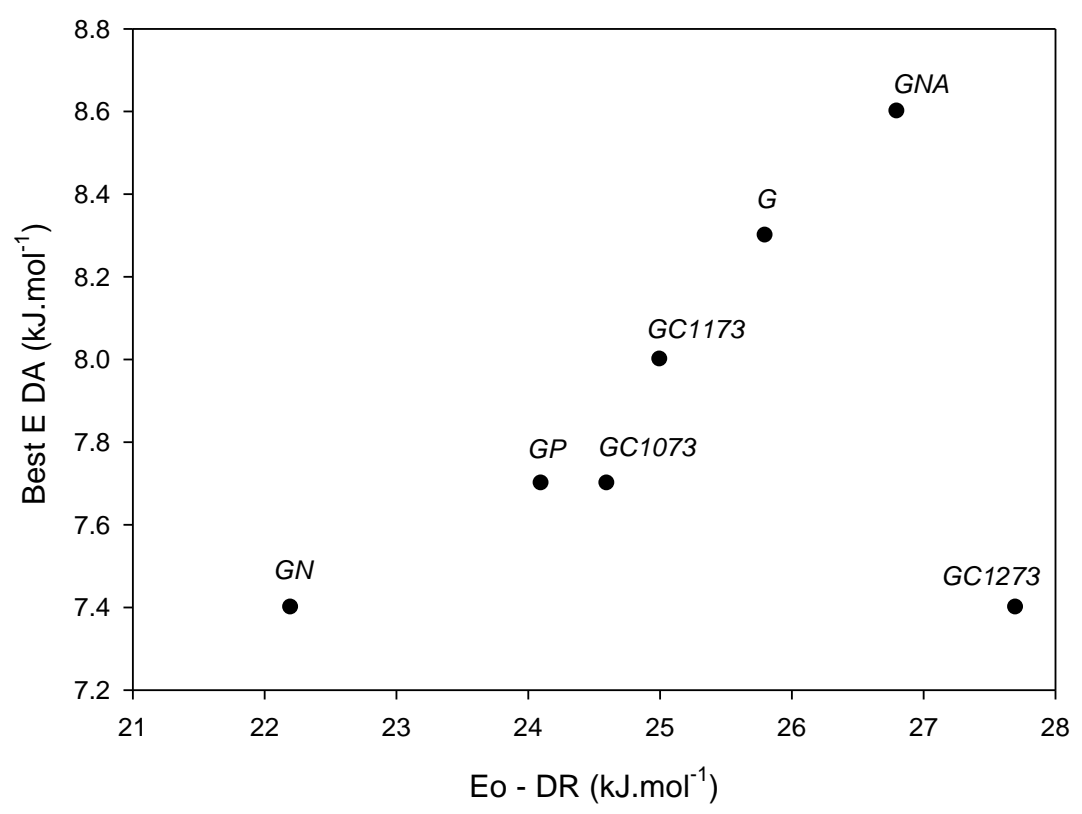

Figure 2. The relationship between the Eo parameters of the equation of DR and E of the equation of DA.

The pore size distribution, calculated from the Quenched Solid Density Functional Theory (QSDFT) model, is shown in Figure 3, which indicates the rough surface, the chemical heterogeneity of the activated carbons, and the effect that the impregnations caused on the microporous structure of the original sample G [18]. For samples in the study, the kernel that represented the best settings between 0.028 and $0.130 \%$ indicates that the activated carbons have a geometry composed of pores in a cylindrical and slit shape, with a high degree of activation that leads to significant microporosity. 


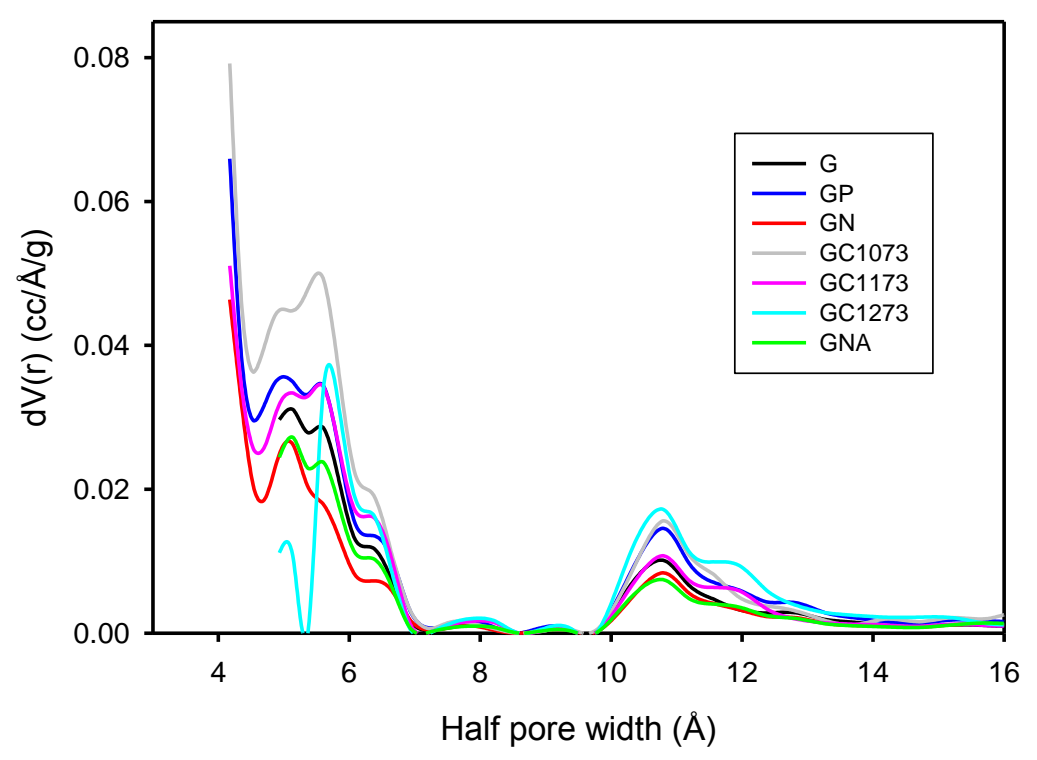

Figure 3. Distribution of micropore size from QSDFT model.

Figure 3 shows that there are 4 peaks of micropores present in the samples around 4, 5, 6, and $11 \AA$. The greatest amount is around $4 \AA$; it is also noted that the carbonisation to $1273 \mathrm{~K}$ generates a loss of the microporosity by around $4 \AA$, while the carbonisation to $1073 \mathrm{~K}$ allows access to new microporosity, which is reflected in the increase in micropores around $4 \AA$ and 5 to $7 \AA$.

\subsection{Adsorption of Phenol during the Immersion Process}

An interesting aspect of this study is the fact that during the calorimetric experience, the adsorption of phenol generated a quantity of heat that is proportional to the solid-liquid interactions. The adsorption of phenol on the activated carbons was carried out for a period of $2 \mathrm{~h}$; this corresponds to a calorimetric measurement. A modification to the Langmuir model proposed by VanDer Kamp and collaborators [3] was used to describe the adsorption process from a solution of activated carbons using the results obtained. This model was used because it allows an evaluation between two types of interactions: a specific enthalpy-driven and another non-specific measurement wherever the adsorption occurs between the fundamental surface of the activated carbon and the non-polar parties in the molecules by hydrophobic links. The Modified Langmuir model is given by the following Equation:

$$
q_{e}=\frac{K_{1} K_{2} C_{e}}{1+K_{1} C_{e}}+K_{H B}
$$

in which qe $\left(\mathrm{mmol} \cdot \mathrm{g}^{-1}\right)$ represents the quantity of phenol adsorbed on the balance, $C_{e}\left(\mathrm{mmol} \cdot \mathrm{L}^{-1}\right)$ is the final concentration of phenol in the solution, $K_{1}\left(\mathrm{~L} \cdot \mathrm{mmol}^{-1}\right)$ is a constant of affinity associated with the amount of polar groups on the surface of the activated carbon, $K_{2}\left(\mathrm{mmol} \cdot \mathrm{g}^{-1}\right)$ is the adsorption capacity of the adsorbent by the solute, and $K_{H B}\left(\mathrm{mmol} \cdot \mathrm{g}^{-1}\right)$ is a constant that allows the non-specific adsorption to be determined through hydrophobic links between the non-polar parties in the adsorbate and the basal carbon surface.

The adsorption isotherms of phenol obtained during the calorimetric determinations adjusted to the Modified Langmuir model are shown in Figure 4.

Figure 4 shows the phenol adsorption on activated carbons during the first two hours of the adsorption process. These are similar to type $\mathrm{L}$ or Langmuir isotherms according to the classification established by Giles for the adsorption of a solid-liquid [19]. This adjustment would indicate that the molecules adsorbed are arranged horizontally on the surface of the activated carbon, that there 
is strong competition between the water and the solute by the adsorption sites, and that there are attractions between the adsorbate molecules.

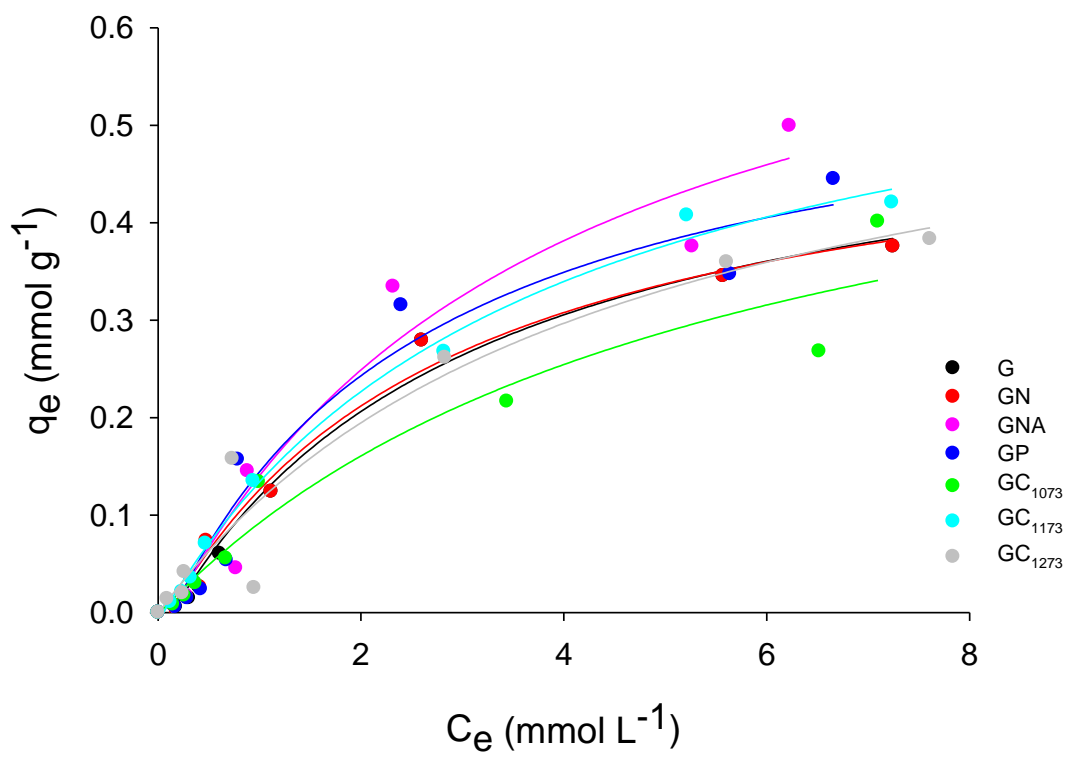

Figure 4. The adsorption isotherms of phenol from aqueous solution for the adsorption process in the calorimeter. The lines correspond to the adjustment of the data in the Langmuir Modified Model.

Table 2 presents the parameters resulting from the adjustment of adsorption data obtained during the calorimetric determination to the modified Langmuir model. For comparative purposes, the adjustments of adsorption data results to the Langmuir model are presented.

Table 2. Setting parameters to the Langmuir and Langmuir models modified for the adsorption of phenol from aqueous solution for the process of adsorption of $2 \mathrm{~h}$.

\begin{tabular}{|c|c|c|c|c|c|c|c|}
\hline \multirow[b]{2}{*}{ Samples } & \multicolumn{4}{|c|}{ Modified Model of Langmuir } & \multicolumn{3}{|c|}{ Langmuir Model } \\
\hline & $K_{1}$ & $\mathbf{K}_{2}$ & $\mathrm{~K}_{\mathrm{HB}}$ & $\mathbf{R}$ & $Q_{0}$ & $\mathrm{~K}_{\mathrm{L}}$ & $\mathbf{R}$ \\
\hline & $\mathrm{L} \cdot \mathrm{mmol}^{-1}$ & $\mathrm{mmol} \cdot \mathrm{g}^{-1}$ & $\mathrm{mmol} \cdot \mathrm{g}^{-1}$ & & $\mathrm{mmol} \cdot \mathrm{g}^{-1}$ & $\mathrm{~L} \cdot \mathrm{mmol}^{-1}$ & \\
\hline$G$ & 0.336 & 0.578 & -0.0263 & 0.993 & 0.612 & 0.238 & 0.989 \\
\hline GN & 0.359 & 0.559 & -0.0216 & 0.993 & 0.583 & 0.269 & 0.990 \\
\hline GNA & 0.270 & 0.786 & -0.0271 & 0.977 & 0.870 & 0.189 & 0.973 \\
\hline GP & 0.400 & 0.621 & -0.0332 & 0.976 & 0.657 & 0.270 & 0.971 \\
\hline $\mathrm{GC}_{1073}$ & 0.183 & 0.606 & -0.0018 & 0.967 & 0.618 & 0.174 & 0.970 \\
\hline $\mathrm{GC}_{1173}$ & 2.273 & 0.668 & -0.0096 & 0.997 & 0.693 & 0.236 & 0.997 \\
\hline $\mathrm{GC}_{1273}$ & 0.229 & 0.623 & -0.0010 & 0.967 & 0.625 & 0.225 & 0.967 \\
\hline
\end{tabular}

Table 2 shows that the highest adsorption value is obtained for the activated carbon impregnated with nitric acid and subsequently kept on to reflux with a solution of ammonium hydroxide, GNA, and that the lowest adsorption is presented for the activated carbon subjected to oxidation with nitric acid, GN. The adsorption is analysed from the values of the constants associated with the adsorption capacity of the activated carbons $Q_{o}$ and $K_{2}$ of Langmuir and Langmuir modified models, respectively.

The $\mathrm{pH}$ values at the end of each calorimetric determination were measured; the results are shown in Figure 5.

Figure 5 shows that the $\mathrm{pH}$ values for GNA sample were between 6.5 and 7.6 and for the GN sample were between 5.3 and 7.3. Taking into account that the pKa value for phenol is 9.98 [20], this is protoned just like the polar groups on the activated carbon surface. The activated carbon GN contains many acid groups, mainly carboxyl groups on the surface by impregnation with nitric acid 
solution (Table 3, chemical parameters obtained from Boehm Titration and $\mathrm{pH}$ in point of zero charge, $\mathrm{pH}_{\mathrm{PZC}}$ ) [21], while for the activated carbon GNA, some acid groups were utilised to incorporate nitrogen as a different heteroatom to oxygen. Nitrogen has a couple of unpaired electrons that allow it to form a link with hydrogen by hydrogen bonds; that is to say, the adsorption of phenol on the GNA sample is greater than other activated carbon samples, because there are more hydrogen bonds between the phenol and the activated carbon surface.

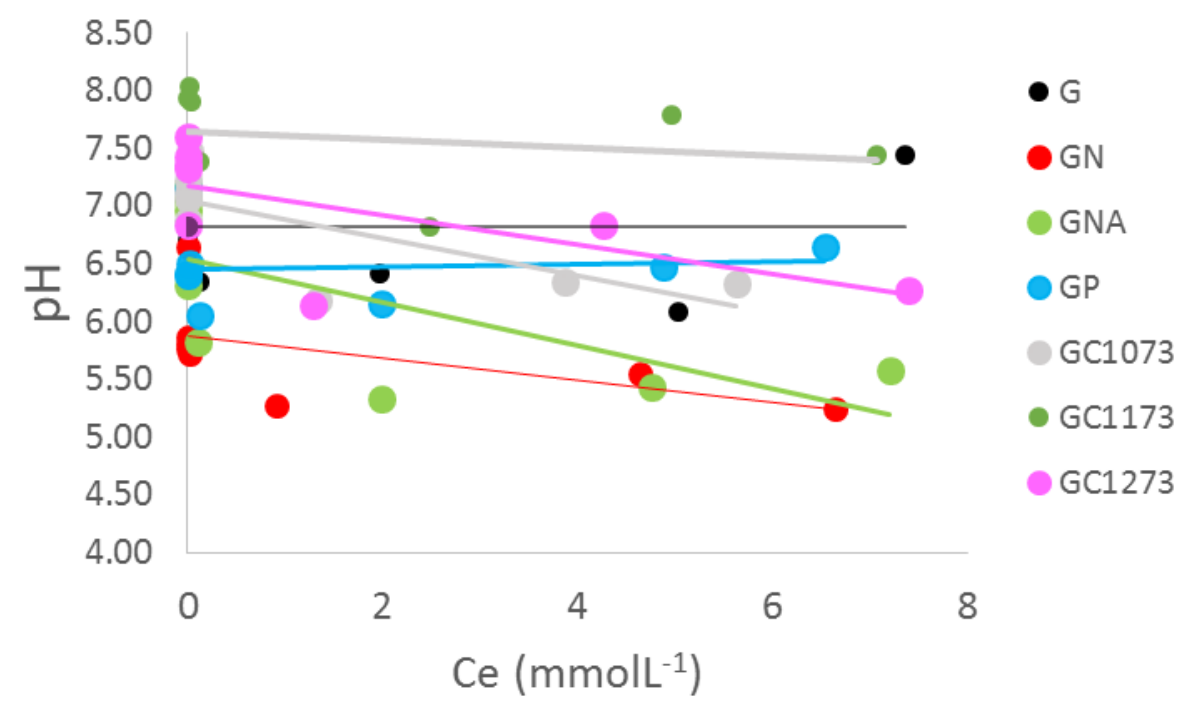

Figure 5. $\mathrm{pH}$ values for the phenol adsorption process during the two hours of the calorimetric determination. The lines correspond to the tendency of the dates.

Table 3. Chemical parameters of the activated carbons.

\begin{tabular}{|c|c|c|c|c|c|c|}
\hline Samples & $\begin{array}{l}\text { Total Acidity } \\
\left(\mu \mathrm{mol} \mathrm{g}^{-1}\right)\end{array}$ & $\begin{array}{c}\text { Total Basicity } \\
\left.(\mu \mathrm{mol} \mathrm{g})^{-1}\right)\end{array}$ & $\begin{array}{l}\text { Carboxílic Groups } \\
\left.\quad(\mu \mathrm{mol} \mathrm{g})^{-1}\right)\end{array}$ & $\begin{array}{l}\text { Lactonic Groups } \\
\quad\left(\mu \mathrm{mol} \mathrm{g} \mathrm{g}^{-1}\right)\end{array}$ & $\begin{array}{l}\text { Phenolic Groups } \\
\left.\quad(\mu \mathrm{mol} \mathrm{g})^{-1}\right)\end{array}$ & $\mathrm{pH}_{\mathrm{PZC}}$ \\
\hline G & 90.5 & 742 & 22.2 & 21.8 & 46.6 & 7.48 \\
\hline GN & 6560 & 735 & 106 & 489.5 & 59.9 & 3.13 \\
\hline GNA & 377 & 799 & 63.2 & 289 & 24.6 & 7.41 \\
\hline GP & 423 & 849 & 109 & 137 & 177 & 5.91 \\
\hline $\mathrm{GC}_{1073}$ & 93.6 & 1210 & 66.1 & 21.2 & 6.36 & 7.65 \\
\hline $\mathrm{GC}_{1173}$ & 93.0 & 1630 & 65.5 & 23.8 & 3.71 & 7.89 \\
\hline $\mathrm{GC}_{1273}$ & 94.1 & 2040 & 64.7 & 46.8 & 17.5 & 9.97 \\
\hline
\end{tabular}

Table 2 also shows the constant $\mathrm{K}_{\mathrm{HB}}$ values; this represents the non-specific interactions between the adsorbate and adsorbent. The modified Langmuir model includes two terms: the first has the general shape of the Langmuir model, with the difference being that the adsorption capacity of Langmuir is represented by the product of the constants $K_{1}$ and $K_{2}$. The second term corresponds to the $\mathrm{K}_{\mathrm{HB}}$ constant; when its value is lower, the hydrophobic interactions are lower too. In this case, the lower values were obtained for G, GN, GNA, and GP samples, which have a higher number of oxygenated groups on the surface. The carbonised samples $\mathrm{GC}_{1073}, \mathrm{GC}_{1173}$, and $\mathrm{GC}_{1273}$ presented fewer negative values for $\mathrm{K}_{\mathrm{HB}}$. These results are in agreement with those obtained by VanDer Kamp [3], which show that the constant $\mathrm{K}_{\mathrm{HB}}$ increases as the fraction of uncovered area of activated carbon is incremented.

\subsection{Adsorption of Phenol at Equilibrium}

For comparative purposes, Figure 6 shows the isotherms obtained in the phenol adsorption process on activated carbons at $291 \mathrm{~K}$ until equilibrium is reached. These isotherms were also studied with regard to the Langmuir and modified Langmuir models. 


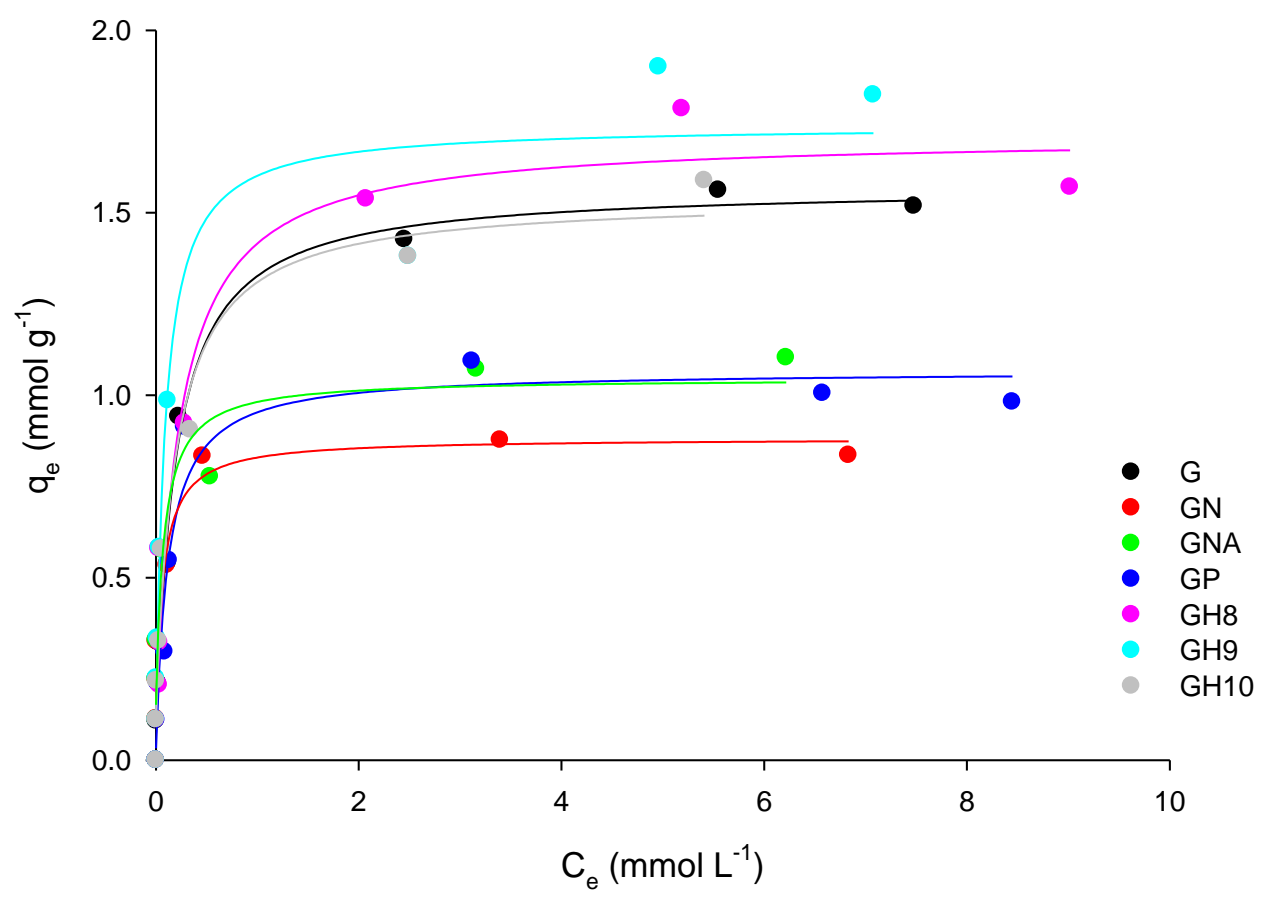

Figure 6. The phenol adsorption isotherms on activated carbons at $291 \mathrm{~K}$. The lines correspond to the adjustment of adsorption data for the modified model of Langmuir.

Figure 6 shows the changes in the interaction between phenol and activated carbon at equilibrium due to contact time. In this case, the adsorption increased compared to the adsorption that occurs in the calorimetric immersion process. The parameters obtained for the adsorption of phenol data in the equilibrium at $291 \mathrm{~K}$ are summarized in Table 4.

Table 4. Adjustment parameters to the Langmuir and Langmuir modified models for the adsorption of phenol from aqueous solution in equilibrium.

\begin{tabular}{|c|c|c|c|c|c|c|c|}
\hline \multirow[b]{2}{*}{ Samples } & \multicolumn{4}{|c|}{ Modified Model of Langmuir } & \multicolumn{3}{|c|}{ Langmuir Model } \\
\hline & K1 & K2 & $\mathrm{K}_{\mathrm{HB}}$ & $\mathbf{R}$ & $Q_{0}$ & KL & $\mathbf{R}$ \\
\hline & $\mathrm{L} \cdot \mathrm{mmol}^{-1}$ & $\mathrm{mmol} \cdot \mathrm{g}^{-1}$ & $\mathrm{mmol} \cdot \mathrm{g}^{-1}$ & & $\mathrm{mmol} \cdot \mathrm{g}^{-1}$ & $\mathrm{~L} \cdot \mathrm{mmol}^{-1}$ & \\
\hline G & 5.03 & 1.51 & 0.074 & 0.995 & 1.57 & 6.01 & 0.990 \\
\hline GN & 370. & 0.73 & 0.155 & 0.964 & 0.76 & 464 & 0.954 \\
\hline GNA & 19.5 & 0.89 & 0.151 & 0.967 & 0.90 & 152 & 0.939 \\
\hline GP & 8.12 & 1.07 & 0.034 & 0.976 & 1.06 & 8.78 & 0.975 \\
\hline $\mathrm{GC}_{1073}$ & 3.65 & 1.67 & 0.129 & 0.981 & 1.67 & 6.50 & 0.977 \\
\hline $\mathrm{GC}_{1173}$ & 11.9 & 1.58 & 0.097 & 0.982 & 1.73 & 13.8 & 0.978 \\
\hline $\mathrm{GC}_{1273}$ & 5.08 & 1.41 & 0.131 & 0.987 & 1.35 & 11.5 & 0.961 \\
\hline
\end{tabular}

The main difference between these two groups of activated carbons is that the first corresponds to those samples that were carbonised and the original activated carbon. These samples have a greater portion of graphene surface due to the carbonisation process. The second group corresponds to the activated carbons that were impregnated, and which therefore contain more oxygenated groups on the surface. These results indicate that the initial adsorption is specific between the phenol and the groups on the surface, while the non-specific interactions between the hydrophobic sites in the solute and the surface of the activated carbons require more time, because they are mainly $\pi-\pi$ interactions [7].

According to VanDer Kamp, the hydrophobic links are entropic process-driven, and are the result of a loss of water around the non-polar sites of adsorbate molecules, while specific adsorption is an enthalpy-driven process [3,22]. 
It is also noteworthy that in all cases presented, the constant $\mathrm{K}_{\mathrm{HB}}$ increased with respect to the values obtained from the adsorption in the calorimeter. This suggests that the presence of functional groups on the surface of the activated carbons are a center of primary adsorption; at the end of the process, the adsorption is performed on the exposed surface of the activated carbons. It can also be seen that the GN and GNA samples presented similar values for the $\mathrm{K}_{\mathrm{HB}}$ constant. This indicates that the reflux performed with ammonia to activated carbon GN does not change the basal surface of the activated carbon; rather, the reaction is carried out between ammonia and the oxygenated groups on the surface, producing nitrogen groups.

The values of $\mathrm{K}_{\mathrm{HB}}$ for samples $\mathrm{G}, \mathrm{GC}_{1073}, \mathrm{C}_{1173}$, and $\mathrm{GC}_{1273}$ increase in the order $\mathrm{G}<\mathrm{GC}_{1173}<$ $\mathrm{GC}_{1073}<\mathrm{GC}_{1273}$, showing that the carbonisation process increases the exposed surface, as well as increasing the surface area of the activated carbon, as noted in Table 1 ; therefore, the carbonisation processes favour the non-specific interactions with phenol. The carbonisation at $1273 \mathrm{~K}$ (sample $\mathrm{GC}_{1273}$ ) resulted in the loss of microporous structure that was around 0.4 and $0.5 \mathrm{~nm}$, as noted in Figure 2. This could indicate that the non-specific interactions between the phenol and the activated carbon were favoured by the loss of microporosity and the oxygenated groups on the surface.

\subsection{Determination of the Immersion Enthalpy of Activated Carbons in Phenol Aqueous Solutions}

Figure 7 presents some potentiometric curves obtained during the immersion of activated carbon modified with nitric acid in phenol solutions and subsequently subjected to reflux in ammonium hydroxide solution GNA. The curves presented in this figure correspond to those obtained in the process of immersion of the activated carbon in the phenol solutions. The total calorimetric curves include the calibration process that is carried out for all solids; the contact between activated carbon and the phenol solution is maintained for two hours, so the adsorption of phenol is carried out at the same time.

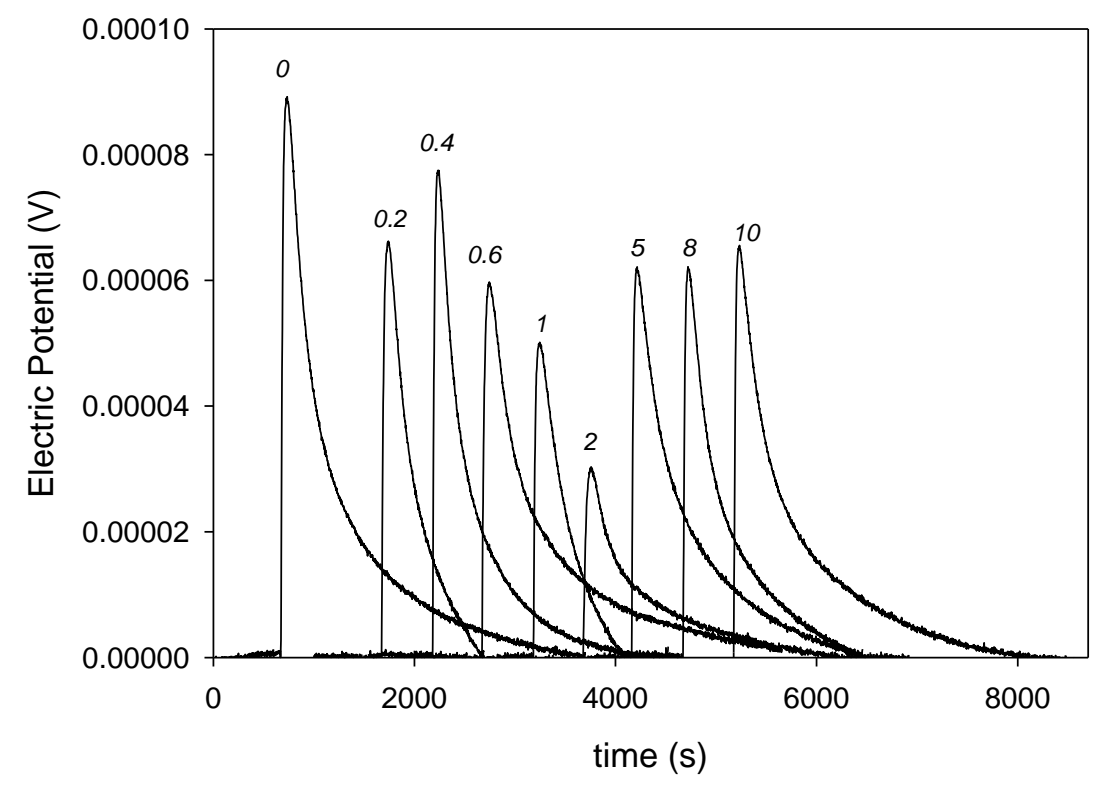

Figure 7. Potentiometric curves obtained during the immersion calorimetry for the activated carbon sample GNA in solutions of phenol; the numbers over peaks correspond to the concentration of phenol at the beginning of the calorimetry immersion in $\mathrm{mmol} \cdot \mathrm{L}^{-1}$.

In Figure 7, the area under the curve is proportional to the energy transferred as heat during the immersion calorimetry processes; the concentration of phenol of each peak is equal to those used in the generation of the adsorption isotherm. It is well known that the immersion energy is an integral quantity that corresponds to the average interactions with the solid and all constituents of the liquid 
phase [4]. The first peak corresponds to energy produced by the wetting of the carbon surface, which is the largest; the peaks from two to six correspond to the fast adsorption in the isotherm, and it can be see that the area of these peaks decreases as the phenol concentration increases. This suggests that the energy produced by the wetting of activated carbon is used by phenol for adsorption; the last three peaks are the plateau in the adsorption isotherm and show that the immersion energy is similar and therefore there is no increase in adsorption.

An interesting result of this study can be seen when comparing the maximum capacities of the adsorption $\mathrm{Q}_{\mathrm{o}}$ in the Langmuir model during the calorimetric and the equilibrium process (Figure 8). As can be observed, for the sample GNA, the adsorption on the calorimeter was carried out at $97 \%$. This suggests the energetic interactions produced by the phenol adsorption and determines the heat transferred using the calorimetric immersion for this sample; this corresponds to almost all of the energy produced during the entire adsorption process. This indicates that the adsorption of phenol on activated carbon GNA involves specific interactions that are given by enthalpy-driven processes.

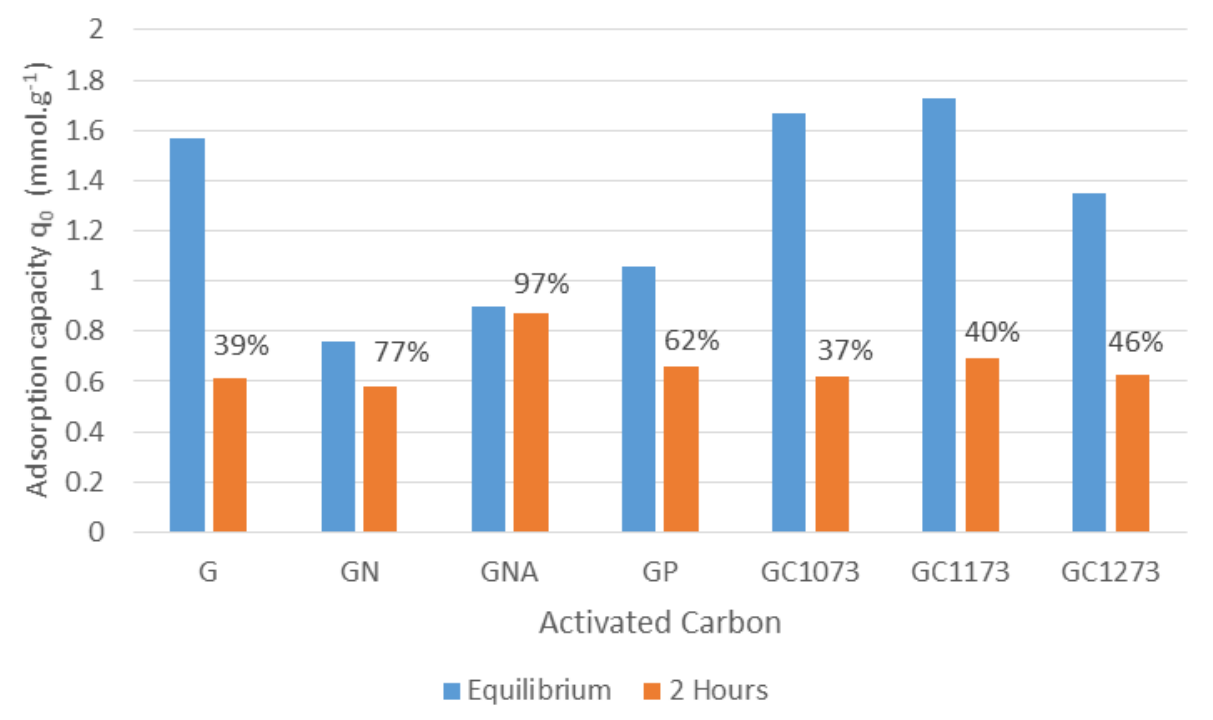

Figure 8. Comparison between the adsorption in the calorimeter until equilibrium was reached and the maximum capacity of adsorption $Q_{o}$ from the Langmuir model.

\subsection{Immersion Enthalpies of Activated Carbons as a Function of Phenol Concentration}

Figure 9 shows the change in adsorption enthalpy of activated carbons as a function of the phenol adsorbed on the samples G, GN, and GNA.

The immersion enthalpy determined from the calorimetric results is the energy transferred in the form of heat by water adsorption, displacement of this, and, finally, the adsorption of phenol $[4,23,24]$. In other words, the heat determined involves the interactions of water and phenol, phenol and the activated carbon surface, and water and the surface of the activated carbon. When the process of immersion in water is performed, the heat transferred by the interactions between molecules of water and water molecules and the surface of the activated carbon can be determined. When the enthalpy of immersion in a solution is determined, it is possible to evaluate the solute-solvent and solute-surface interactions. These processes are involved during the adsorption. By subtracting the enthalpy of immersion in water from the enthalpy of immersion in solution, the value obtained is called the enthalpy of adsorption. This is the result presented in Figure 8.

Figure 9 shows that for sample $G$, the values of enthalpy indicate that the adsorption is an exothermic process. When the phenol is less than $1 \mathrm{mmol} \cdot \mathrm{L}^{-1}$, as the phenol concentration increases, the enthalpy increases; this behaviour could be attributed to the formation of the monolayer. For concentrations of phenol between 2 and $8 \mathrm{mmol} \cdot \mathrm{L}^{-1}$, a plateau presents, which could indicate that the heat produced by the adsorption is distributed between the molecules of phenol and water in the 
interface to search for a stable arrangement. For concentrations of phenol adsorbed above $8 \mathrm{mmol} \cdot \mathrm{L}^{-1}$, there is an increase in the amount adsorbed. This could be associated with the formation of other layers of phenol on the surface. It should be noted that this behaviour shows that the interaction of water with the surface of the activated carbon is low, and therefore the heat produced corresponds to the interactions of phenol and its surface.

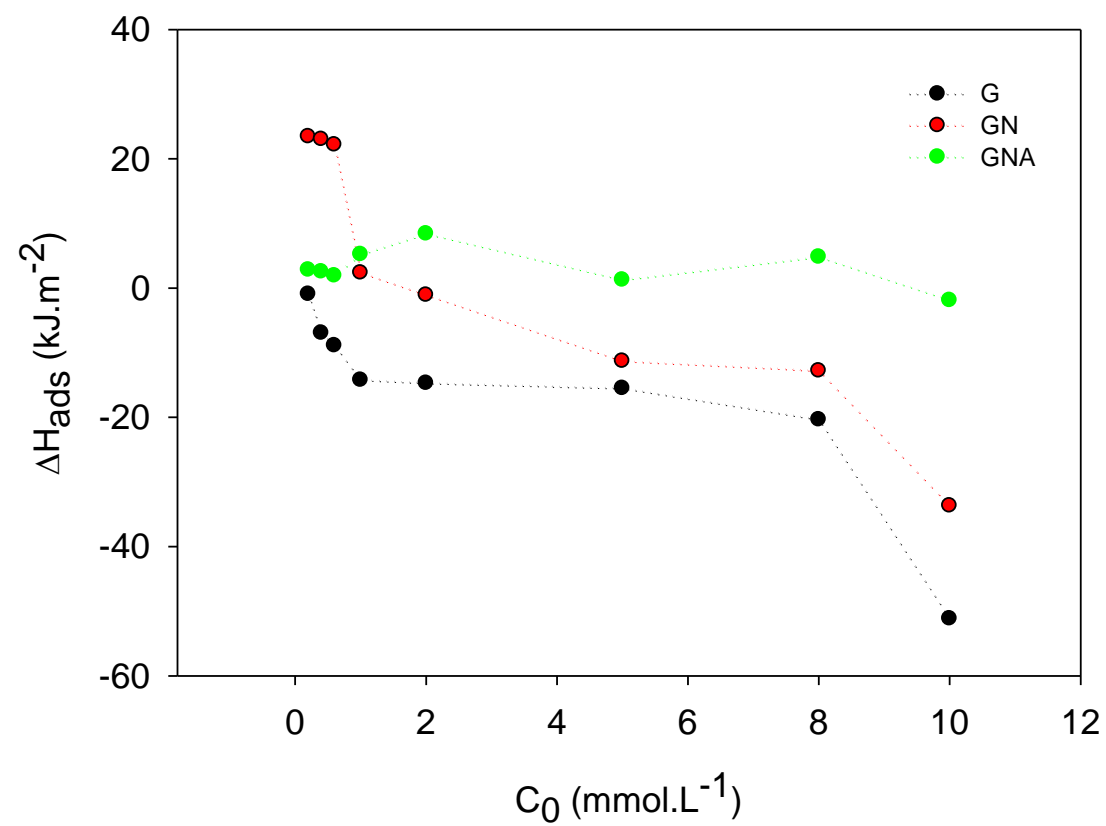

Figure 9. Changing the enthalpy as a function of the phenol concentration in the solution.

For the sample oxidised with nitric acid (sample GN), it can be observed that for quantities of phenol adsorbed below $1 \mathrm{mmol} \cdot \mathrm{L}^{-1}$, the values of enthalpy obtained are positive. This indicates that the presence of acid groups on the activated carbon surface favours the interaction of water with this by the formation of hydrogen bonds. Therefore, the process of the adsorption of phenol requires energy to remove the water molecules of the surface. For quantities of phenol adsorbed above $2 \mathrm{mmol} \cdot \mathrm{L}^{-1}$, the behaviour is similar to that which occurs with the sample G. In terms of the sample GNA, the behaviour is different, since the enthalpy values are positive in the entire range of adsorption. This could be an indication that the interactions of the water and the surface are stronger, and therefore more energy will be required to desorb water molecules and adsorb the phenol molecules.

Taking into account that the activated carbons are heterogeneous surfaces, the immersion enthalpy in water and benzene were compared in order to determine the degree of hydrophobicity of the activated carbons surface. Table 5 presents the results obtained for the immersion enthalpies for samples in water and benzene, and the calculation of the hydrophobic factor.

Table 5. Immersion enthalpies in water and benzene, and hydrophobic factor.

\begin{tabular}{|c|c|c|c|}
\hline \multirow{2}{*}{ Sample } & $\Delta \mathrm{H}_{\mathrm{inm}} \mathrm{H}_{2} \mathrm{O}$ & $\Delta \mathrm{H}_{\mathrm{inm}} \mathrm{C}_{6} \mathrm{H}_{6}$ & Hydrophobicity Factor \\
\hline & $\left(J \cdot g^{-1}\right)$ & $\left(J \cdot g^{-1}\right)$ & $\frac{\mathrm{H}_{\text {imm }} \mathrm{C}_{6} \mathrm{H}_{6}}{\mathrm{U}_{\text {imm }} \mathrm{H}_{2} \mathrm{O}}$ \\
\hline G & -11.0 & -60.6 & 5.5 \\
\hline GN & -24.7 & -53.9 & 2.2 \\
\hline GNA & -17.9 & -49.9 & 2.8 \\
\hline GP & -24.8 & -80.6 & 3.3 \\
\hline $\mathrm{GC}_{1073}$ & -17.7 & -122.3 & 6.9 \\
\hline $\mathrm{GC}_{1173}$ & -23.7 & -103.6 & 4.4 \\
\hline $\mathrm{GC}_{1273}$ & -21.3 & -100.1 & 4.7 \\
\hline
\end{tabular}


In Table 5, it can be seen that the hydrophobic factors obtained for the activated carbons GN, GNA, and GP presented the lowest values, which confirms that the impregnation carried out increased the number of oxygenated groups on the surface. It can also be seen that the carbonisation of the activated carbon $\mathrm{G}$ decreases the number of oxygenated groups on the surface, which is reflected in the increase in hydrophobicity of the carbonised samples $\mathrm{GC}_{1073}, \mathrm{GC}_{1173}$, and $\mathrm{GC}_{1273}$.

In Figure 10, it can be seen that the samples with higher values of the constant $K_{1}$, which is associated with the amount of polar groups on the activated carbon surface, presented the lowest values of hydrophobic factor. This is consistent with the fact that these samples have a greater number of oxygenated groups on the surface due to the oxidation processes. The carbonised samples $\mathrm{GC}_{1073}$, $\mathrm{GC}_{1173}$, and $\mathrm{GC}_{1273}$ presented the highest hydrophobic factors and the lowest values for $\mathrm{K}_{1}$; these results indicate that the $\mathrm{K}_{1}$ constant of the modified Langmuir model is appropriate for determining the presence of polar groups on the activated carbon surface.

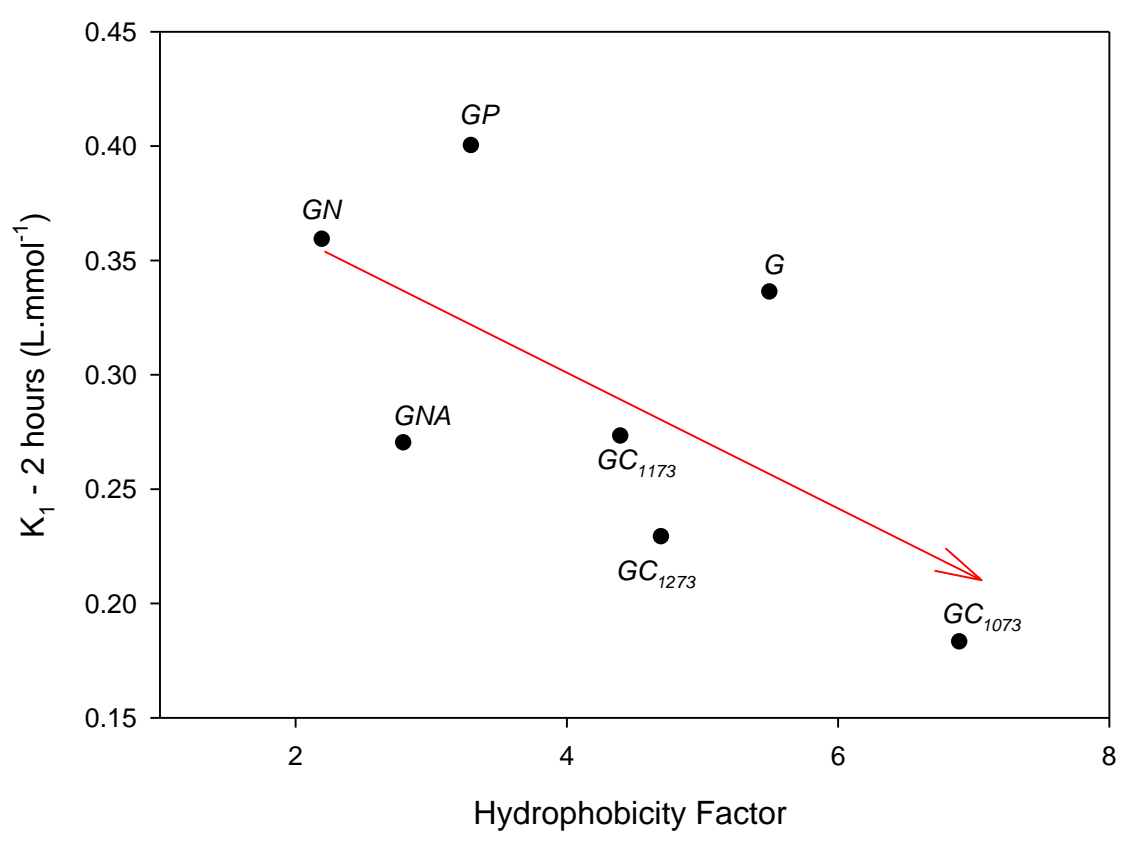

Figure 10. Correlation between $\mathrm{K}_{1}$ of the modified Langmuir model and the hydrophobic factor.

Figure 11 presents the molar enthalpies of immersion as a function of the quantity of phenol adsorbed per square meter of activated carbon surface.

Figure 11 shows that as the quantity of phenol adsorbed increases, the enthalpy values per mol decrease; this behaviour can be associated with the formation of the monolayer. The results shown in this Figure are interesting, because they indicate that the greater interaction between the activated carbon and the solution is obtained for the solid GNA and $\mathrm{GC}_{1073}$. These samples presented the greatest amount adsorbed of phenol, and its decline in the immersion enthalpy is higher. For the activated carbons $\mathrm{G}$ and $\mathrm{GN}$, the values of immersion enthalpy constants are higher, indicating a lower solid-solution interaction. 


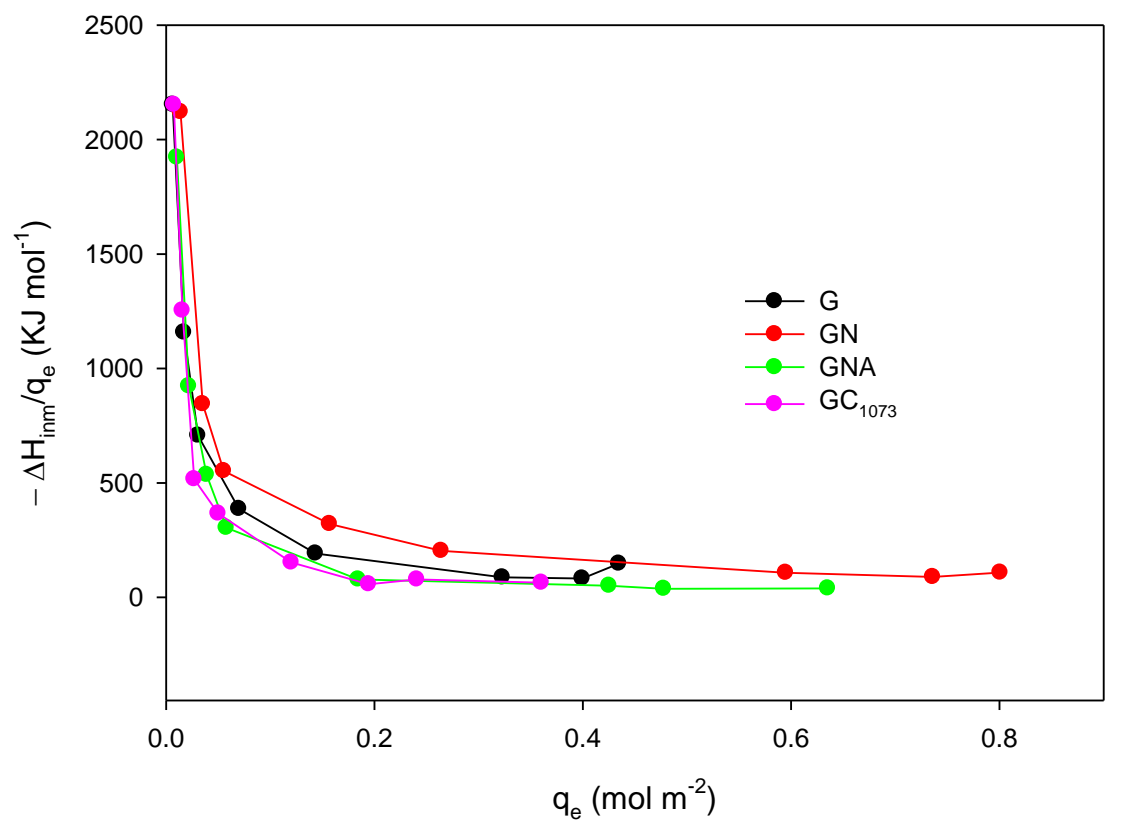

Figure 11. Relationship between the quantity of phenol adsorbed on the interface per unit of area and the immersion enthalpy per mole of phenol adsorbed on the interface for samples G, GN, GNA, and $\mathrm{GC}_{1073}$.

\section{Conclusions}

From the $\mathrm{n}$ parameter of the Dubinin-Astakhov equation, it was found that the activated carbons are heterogeneous and that as the parameter of heterogeneity from this model moves away from 2, there are significant differences between the values of the micropores energy Eo and E obtained by the Dubinin-Radushkevich and Dubinin-Astakhov models, respectively.

The determination of the pore size distribution calculated from the Quenched Solid Density Functional Theory (QSDFT) model showed that the impregnation and carbonisation processes modified the microporous structure of granular carbon, increasing it for the carbonised to $1073 \mathrm{~K}$ and decreasing it for the sample carbonised to $1273 \mathrm{~K}$.

The description of the phenol adsorption process on the surface of the activated carbons can be performed using the immersion calorimetric technique when is involves specific interactions that are given by enthalpy-driven processes, since a quantity of heat proportional to the interactions between the solid and the fluid is generated during the immersion, and it can be determined by this technique.

The modified Langmuir model allows evaluation of the specific and non-specific interactions between the solute and the surface area and, therefore, the evaluation of changes in the interactions produced by the modifications.

The sample impregnated with nitric acid and subsequently subjected to reflux in ammonium hydroxide solution, GNA, showed the highest values of phenol adsorption during the calorimetric process, while the activated carbon impregnated with nitric acid, GN, presented the lowest adsorption values. The treatment with nitric acid introduced acidic groups to the activated carbon surface, and the subsequent reflux in ammonium hydroxide solution allowed the formation of nitrogen groups, which increased interactions between phenol and activated carbon surface by hydrogen bonds.

To compare the amount of phenol adsorbed on the monolayer on the activated carbon, GNA, during calorimetry with the equilibrium processes from $Q_{0}$ of the Langmuir model, it was found that $97 \%$ of the adsorption was carried out in the first two hours of adsorption. Therefore, the heat transferred by interactions between the solute and the surface determined by calorimetry corresponds to almost all of the energy produced during the whole adsorption process. 
The immersion enthalpy values in phenol solutions showed that the oxygenated groups on the activated carbon surface increase the surface-water interactions; therefore, energy is required to move water from the surface and to adsorb phenol. This implies that the enthalpy values obtained during the phenol adsorption process would diminish when the activation has a greater number of oxygenated groups on the surface.

Author Contributions: A.M.C.-B.: experimental development and writing preparation L.G., F.G.-G. and J.C.M.-P.: experimental design, review of results and direction of the investigation.

Acknowledgments: The authors thank the Framework Agreement between the Universidad de los Andes (Colombia) and the Universidad Nacional de Colombia and the act of agreement established between the Chemistry Departments of the two universities. The authors also appreciate the grant for the funding of research programs for Associate Professors, Full Professors, and Emeritus Professors, announced by the Faculty of Sciences of the Universidad de los Andes (Colombia), 28 November 2017, 2018-2019, according to the project "Thermodynamic Characterization of the Adsorption of Contaminants on Porous Adsorbents".

Conflicts of Interest: The author(s) declared no potential conflicts of interest with respect to the research, authorship, and/or publication of this article.

\section{References}

1. Yorgun, S.; Ylldız, D. Preparation and characterization of activated carbons from paulownia wood by chemical activation with h3po4. J. Taiwan Inst. Chem. Eng. 2015, 53, 122-131. [CrossRef]

2. Anisuzzaman, S.M.; Bono, A.; Krishnaiah, D.; Tan, Y.Z. A study on dynamic simulation of phenol adsorption in activated carbon packed bed column. J. King Saud Univ. Eng. Sci. 2016, 28, 47-55. [CrossRef]

3. VanDer Kamp, K.A.; Qiang, D.; Aburub, A.; Wurster, D.E. Modified langmuir-like model for modeling the adsorption from aqueous solutions by activated carbons. Langmuir 2005, 21, 217-224. [CrossRef] [PubMed]

4. Denoyel, R.; Rouquerol, F.; Rouquerol, J. Chapter twelve-Porous texture and surface characterization from liquid-solid interactions: Immersion calorimetry and adsorption from solution. In Adsorption by Carbons; Bottani, E.J., Tascón, J.M.D., Eds.; Elsevier: Amsterdam, The Netherlands, 2008; pp. 273-300.

5. Silvestre-Albero, J.; Gómez de Salazar, C.; Sepúlveda-Escribano, A.; Rodríguez-Reinoso, F. Characterization of microporous solids by immersion calorimetry. Colloids Surf. A Physicochem. Eng. Asp. 2001, 187-188, 151-165. [CrossRef]

6. Rouquerol, J.; Rouquerol, F.; Llewellyn, P.; Maurin, G.; Sing, K.S. Adsorption by Powders and Porous Solids: Principles, Methodology and Applications; Academic Press: Cambridge, MA, USA, 2013.

7. Sing, K.S.W. 10-adsorption by active carbons. In Adsorption by Powders and Porous Solids, 2nd ed.; Maurin, F.R.R.S.W.S.L., Ed.; Academic Press: Oxford, UK, 2014; pp. 321-391.

8. Silvestre-Albero, J.; Silvestre-Albero, A.; Rodríguez-Reinoso, F.; Thommes, M. Physical characterization of activated carbons with narrow microporosity by nitrogen (77.4k), carbon dioxide (273k) and argon (87.3k) adsorption in combination with immersion calorimetry. Carbon 2012, 50, 3128-3133. [CrossRef]

9. Carvajal-Bernal, A.M.; Gómez-Granados, F.; Giraldo, L.; Moreno-Piraján, J.C. Calorimetric evaluation of activated carbons modified for phenol and 2,4-dinitrophenol adsorption. Adsorption 2016, 22, 13-21. [CrossRef]

10. Vargas, D.P.; Giraldo, L.; Moreno-Piraján, J.C. Co(2) adsorption on activated carbon honeycomb-monoliths: A comparison of langmuir and tóth models. Int. J. Mol. Sci. 2012, 13, 8388-8397. [CrossRef] [PubMed]

11. Moreno, J.C.; Giraldo, L. Setups for simultaneous measurement of isotherms and adsorption heats. Rev. Sci. Instrum. 2005, 76, 054103. [CrossRef]

12. Brunauer, S.; Emmett, P.H.; Teller, E. Adsorption of gases in multimolecular layers. J. Am. Chem. Soc. 1938, 60, 309-319. [CrossRef]

13. Dubinin, M.; Radushkevich, L. Equation of the characteristic curve of activated charcoal. Chem. Zentr 1947, 1,875 .

14. Thommes, M.; Kaneko, K.; Neimark, A.V.; Olivier, J.P.; Rodriguez-Reinoso, F.; Rouquerol, J.; Sing, K.S. Physisorption of gases, with special reference to the evaluation of surface area and pore size distribution (iupac technical report). Pure Appl. Chem. 2015, 87, 1051-1069. [CrossRef]

15. Yang, G.; Chen, H.; Qin, H.; Feng, Y. Amination of activated carbon for enhancing phenol adsorption: Effect of nitrogen-containing functional groups. Appl. Surface Sci. 2014, 293, 299-305. [CrossRef] 
16. Yin, C.Y.; Aroua, M.K.; Daud, W.M.A.W. Review of modifications of activated carbon for enhancing contaminant uptakes from aqueous solutions. Sep. Purif. Technol. 2007, 52, 403-415. [CrossRef]

17. Jansen, R.; Van Bekkum, H. Amination and ammoxidation of activated carbons. Carbon 1994, 32, 1507-1516. [CrossRef]

18. Van den Hoop, M.; Benegas, J. Colloids and surfaces a: Physicochemical and engineering aspects. Colloids Surf. A Physicochem. Eng. Asp. 2000, 170, 151-160. [CrossRef]

19. Giles, C.H.; MacEwan, T.H.; Nakhwa, S.N.; Smith, D. 786. Studies in adsorption. Part xi. A system of classification of solution adsorption isotherms, and its use in diagnosis of adsorption mechanisms and in measurement of specific surface areas of solids. J. Chem. Soc. (Resumed) 1960, 3973-3993. [CrossRef]

20. Christian, G.D. Química Analitica, 6th ed.; México, D.F., Ed.; MCGraw-Hill/Interamericana Editores: Mexico, 2009.

21. Dąbrowski, A.; Podkościelny, P.; Hubicki, Z.; Barczak, M. Adsorption of phenolic compounds by activated carbon-A critical review. Chemosphere 2005, 58, 1049-1070. [CrossRef] [PubMed]

22. Cortés, J.C.; Giraldo, L.; García, A.A.; García, C.; Moreno, J.C. Oxidación de un carbón activado comercial y caracterización del contenido de grupos ácidos superficiales. Rev. Colomb. Quím. 2008, 37, 55-65.

23. Marsh, H.; Rodríguez-Reinoso, F. Chapter 4-Characterization of activated carbon. In Activated Carbon; Elsevier Science Ltd.: Oxford, UK, 2006; pp. 143-242.

24. Auroux, A. Calorimetry and Thermal Methods in Catalysis; Springer: Berlin, Germany, 2013; Volume 154.

(C) 2018 by the authors. Licensee MDPI, Basel, Switzerland. This article is an open access article distributed under the terms and conditions of the Creative Commons Attribution (CC BY) license (http://creativecommons.org/licenses/by/4.0/). 